\title{
Article
}

\section{Testosterone and Human Behavior: The role of individual and contextual variables}

Carre, Justin and Archer, John

Available at http://clok.uclan.ac.uk/17312/

Carre, Justin and Archer, John ORCID: 0000-0003-0483-1576 (2017)

Testosterone and Human Behavior: The role of individual and contextual variables. Current Opinion in Psychology . ISSN 2352-250X

It is advisable to refer to the publisher's version if you intend to cite from the work. http://dx.doi.org/10.1016/j.copsyc.2017.03.021

For more information about UCLan's research in this area go to http://www.uclan.ac.uk/researchgroups/ and search for < name of research Group>.

For information about Research generally at UCLan please go to http://www.uclan.ac.uk/research/

All outputs in CLoK are protected by Intellectual Property Rights law, including Copyright law. Copyright, IPR and Moral Rights for the works on this site are retained by the individual authors and/or other copyright owners. Terms and conditions for use of this material are defined in the policies page.

\section{CLoK}

Central Lancashire online Knowledge www.clok.uclan.ac.uk 
Testosterone and Human Behavior: The role of individual and contextual variables

\author{
Justin M. Carré \\ Department of Psychology \\ Nipissing University \\ North Bay, Ontario, Canada
}

John Archer

School of Psychology

University of Central Lancashire

Preston, UK 


\section{Abstract}

The study of testosterone and aggression originated in experimental studies of animals, showing a direct causal link in some species. Human studies showed an overall weak correlation between testosterone and aggression. A theoretical framework ("the challenge hypothesis") enabled testosterone-behavior interactions in humans to be framed within a theory that emphasized hormonal responses to competition influencing subsequent aggressive behavior. The short-term administrations of testosterone to young women and to young men showed influences on behavioral and neural processes associated with aggression. Other findings are that testosterone influences aggression in high dominance men, and in those with low cortisol levels; and that testosterone can affect both aggressive and prosocial behavior, within the context of an experimental game. 


\section{Introduction}

Studies showing a link between testosterone and aggression have their origin in experimental studies of animals, first involving domestic fowl [1], and then house mice [2]. These were followed by correlational studies with humans, using a variety of measures of aggression and of testosterone. From the initial human study [3] to the early 2000s, a meta-analysis of 42 studies found an overall correlation of $r=0.08$ between testosterone and measures of aggression [ $4 *$, associations being greater for samples of younger men and for offenders. Other meta-analyses have found associations in boys, and in women [ $\left.5^{* *}\right]$.

There are three considerations that prevent the conclusion that there is a direct causal link between testosterone and aggression in humans, as there is in a range of vertebrates [6]. First, being successful in competitive situations, including those involving aggression, can lead to increased testosterone; this could accumulate over repeated successes to increase the testosterone levels of more competitive individuals. Second, there is evidence that levels of aggression do not increase at puberty in humans coincidental with rising testosterone levels [7]. Third, several controlled trials of the impact of long-term injections of testosterone on mood and behavior have produced null results overall [5*: Table 2], although studies of the short-term oral administration of testosterone to women show a range of changes, including features associated with aggression [e.g., 8, 9, 10], and with greater activity in brain regions associated with aggression $[11,12,13]$.

\section{The Challenge Hypothesis}

Much of the existing evidence connecting testosterone and behavior in humans can be understood in terms of the evolutionarily-based 'challenge hypothesis', originally applied to birds $[14,15]$. The essence of this hypothesis is that since consistently high levels of testosterone 
have maladaptive consequences, such high levels should be restricted to times of high reproductive competition, particularly in species where there is bi-parental care, as in humans (see 16, for an update of its cope). The Challenge Hypothesis involves a number of predictions for humans: (1) there will be no increased aggression in males at puberty, despite the increased testosterone levels; (2) men will respond to sexual and competitive stimuli with increased testosterone; (3) increased testosterone will lead to more competitive aggression; (4) paternal care will lower testosterone levels. The evidence, first reviewed in the mid-2000s [5**] and subsequently updated [17] broadly supports these predictions.

There is also considerable situational and individual variability, which can sometimes be predicted by the challenge hypothesis. Thus, paternal care is associated with lowering of testosterone levels $[18,19]$. There are also differences in the extent to which individual men prioritize parental or mating behavior, and this is correlated with their testosterone levels [5]. More recent evidence indicates considerable individual and situational variability in the testosterone-behavior link, indicating that this is more nuanced than expected solely from the challenge hypothesis.

\section{Experimental Studies of Short-Term Effects of Testosterone}

A meta-analysis of the correlational studies of hormones and aggression [4] indicated considerable variation in the size of the hormone-behavior link. These earlier studies differed methodologically, and were restricted in several ways, for example reliance on self-reports, single measures of testosterone, and not taking into account context-dependent changes in testosterone. Subsequent experimental studies [for a review, see 17] introduced greater control of both the behavioral measures and the manipulation of testosterone levels. However, they were limited in that they used young women as participants (the physiological protocol was only 
available for women at the time), and thus involved testosterone levels higher than the participants would experience from their endogenous levels. Recent studies have begun to overcome these limitations. It is now possible to investigate the extent to which single administrations of testosterone influence behavioral and neural processes in young men [e.g., 20, $\left.21^{*}, 22\right]$. This research shows both contextual and individual differences in the links between testosterone and aggression.

\section{Establishing the Link Between Testosterone and Aggression}

Although there is inconsistent evidence for a link between trait-level (i.e., baseline) testosterone and human aggression [4*], a growing body of evidence suggests that acute changes in testosterone within the context of competition and/or social provocation may be more relevant for understanding individual differences in human aggression [23*]. For example, two studies reported that acute changes in testosterone concentrations during competition were positively correlated with aggressive behavior measured on the Point Subtraction Aggression Paradigm, an established behavioral measure of reactive aggression in humans [24]. These findings occurred in men, but not women $[25,26]$. Another study demonstrated that a long-term intervention program designed to curtail antisocial behavior in 'at-risk' youth was successful, in part, because it dampened testosterone responses to social provocation [27]. This intervention was implemented in kindergarten, and the children assigned to the intervention condition received social-cognitive-behavioral therapy, whereas those assigned to the control condition received no such treatment. Twenty years after the intervention, participants were recruited for a laboratory session in which they performed the Point Subtraction Aggression Paradigm. The intervention group showed less aggression on the Point Subtraction Aggression Paradigm and decreased testosterone reactivity to social provocation than the control group. Notably, the association 
between assignment to the intervention condition and decreased aggression was statistically mediated by decreased testosterone reactivity to provocation [27]. Collectively, these findings are consistent with experimental research in animals demonstrating that competition-induced changes in testosterone play a key role in modulating aggressive behavior [28, 29]. This research has clearly established a causal role of testosterone in potentiating aggressive behavior.

\section{Pharmacological Challenge Studies}

During the past decade, pharmacological challenge studies indicate that a single dose of testosterone to healthy young women modulates various physiological (threat-related brain function) and behavioral (empathy, attention toward angry faces) processes relevant to human aggression [see $23 *$ for review]. Similar pharmacological challenge studies in men have only recently been conducted. In one study, a single application of testosterone to healthy men rapidly (within 90 mins) increased amygdala, hypothalamus, and periaqueductal grey reactivity to angry facial expressions [21*]. These findings are notable for several reasons: (1) similar effects of exogenous testosterone have been found in women [11, 12]; (2) these subcortical brain structures are rich in both androgen and estrogen receptors [30, 31, 32]; and (3) these regions play a key role in potentiating reactive aggression in animals [33]. Studies outside the scanner have also yielded interesting effects of testosterone on social cognition and behavior. For instance, one study [34] found that a single application of testosterone increased men's perceptions of their own facial dominance. This finding suggests that the link between testosterone and human aggression in men may be due to testosterone's effects on a man's perception of his own physical formidability. In a more recent study [35*], healthy young men $(n=121)$ perform the Point Subtraction Aggression Paradigm after receiving either testosterone or a placebo. Testosterone rapidly (within 60 mins) increased aggression in men, but only to the extent that such men scored 
high on a self-report measure of trait dominance and/or low on a measure of trait self-control. This research is consistent with other experimental and correlational findings indicating that testosterone modulates competitive motivation [36] and aggressive behavior [25], but only among individuals relatively high in trait dominance.

\section{Further Evidence of the Importance of Trait Dominance}

The finding of an interaction between testosterone and trait dominance is highly consistent with other correlational and experimental work. For instance, one study reported that a rise in testosterone among male winners of a competitive interaction predicted increased aggressive behavior in a subsequent task - but only among men scoring relatively high in trait dominance [25]. In another study, individual differences in baseline testosterone concentrations were positively correlated with men's dominance behavior during mate competition, but only for men scoring high in trait dominance [37]. Administration of testosterone to women also increased their competitive motivation after a victory, but only for those scoring high on trait dominance [36]. Collectively, this research highlights the importance of considering individual differences in personality when examining links between neuroendocrine function and human aggression.

\section{Testosterone and the Ultimatum Game}

Other correlational and pharmacological challenge studies examined the role of testosterone in modulating ultimatum game behavior. The ultimatum game is a behavioral economics task whereby a proposer is given a sum of money (e.g., \$10) and has the opportunity to offer as much, or as little money to a receiver. Once the offer is made, the receiver has the choice to either accept or reject the offer. If the offer is accepted, both participants receive their 
split of the money. If the receiver rejects the offer, both participants leave with no money.

Rejection behavior on the ultimatum game can be considered a form of aggressive behavior as its main function is to cause harm (i.e., financial harm) to another individual, following what is considered an unfair offer. Two correlational studies have reported that men and women with relatively high baseline concentrations of testosterone are more likely to reject unfair offers [ $[38$, 39]. In contrast, pharmacological challenge research in both men and women have not found these effects of testosterone on rejection behavior in the ultimatum game [40, 41, 42, 22]. In a recent study [43], researchers investigated the effect of exogenous testosterone on men's punishment and reward behavior following unfair and fair offers in the ultimatum game. They found no effect of testosterone on rejection behavior in the ultimatum game. Nevertheless, men who received testosterone were more likely to pay money to punish proposers who made unfair offers, but at the same time, they were more likely to reward proposers who made fair offers [43]. This work indicates that testosterone can have both antisocial and prosocial effects on behavior depending on context. These findings suggest that rewarding fair proposers, and punishing unfair proposers in the ultimatum game, may be ways in which a person can maintain his or her social status and reputation - and that testosterone plays a key role in modulating status and reputational concerns [see 41].

\section{Testosterone-Cortisol Interactions}

In addition to psychological and contextual moderators, a growing body of work suggests that individual differences in cortisol, the end product of the hypothalamic pituitary adrenal (HPA) axis, affects the degree to which testosterone influences variation in human aggression. In the first study to investigate the moderating role of cortisol [44], researchers found that salivary testosterone concentrations among male teenage inmates (17-18 years old) were positively 
correlated with severity of violent crimes committed, but this effect was only found among males with relatively low salivary cortisol concentrations. Similarly, testosterone concentrations of young adolescent males (12-14 years old) were positively correlated with a self-report measure of overt aggression, but only among males scoring relatively low in cortisol concentrations [45]. Despite these findings, others have reported mixed results - some finding no moderating effects of cortisol [46, 47], and others that testosterone positively predicts aggression and aggressionrelated phenotypes (e.g., psychopathic traits), but only among those with high cortisol concentrations $[48,49]$. Consistent with the literature reviewed above, recent evidence suggests that trait dominance influences the degree to which testosterone and cortisol interact to predict human aggression. Specifically, testosterone positively predicted antisocial punishment, but only among individual scoring low in cortisol and high in trait dominance [50]. Clearly, more research on this topic will be necessary to determine the role that cortisol plays in moderating effects of testosterone on aggression.

\section{Conclusions}

Research on testosterone and human aggression has its roots in animal studies, some of which showed a straightforward causal link in animals, for example in the classic ablation-replacement studies using laboratory mice. Studies on humans followed from the 1970s onwards, when an overall weak association was found between testosterone and aggression, but no effect of longterm injections of testosterone in men. Recent work has progressed via a more subtle theory encompassing the testosterone-aggression link in humans and other animals (the challenge hypothesis) and through methodological advances enabling the short-term effects of hormones to be studied in the laboratory, first in women, and more recently in men. Overall these studies have shown subtleties in the testosterone-behavior relationship, so that it is now clear that this is 
subject to both individual difference and contextual variables, in particular: (1) testosterone influences aggression in high dominance men, and in those with low cortisol levels; and (2) studies with the ultimatum game show that testosterone can affect both aggressive and prosocial behavior. 


\section{References}

[1] Allee WC, Collias NE, Lutherman CZ: Modification of the social order in flocks of hens by injection of testosterone propionate. Physiological Zoology 1939, 12: 412-440.

[2] Beeman AE: The effect of male hormone on aggressive behavior in male mice. Physiological Zoology 1947, 20: 373-405.

[3] Persky H, Smith KD, Basu GK: Relation of psychological measures of aggression and hostility to testosterone production in man. Psychosomatic Medicine 1971, 33: 265-277.

*[4] Archer J, Graham-Kevan N, Davies M: Testosterone and aggression: A reanalysis of Book, Starzyk, and Quinsey's (2001) study. Aggression Viol Behav 2005, 10: 241-261.

A meta-analytic review that comprehensively re-analyzed a previous one, using more explicit decisions rules and careful checking of the data. Overall, only a small association was found between testosterone and aggression over 42 studies.

**[5] Archer J: Testosterone and human aggression: An evaluation of the challenge hypothesis. Neurosci Biobehav Rev 2006, 30: 319-335.

This paper assessed human studies on testosterone-behavior interactions in relation to "the challenge hypothesis", an evolutionarily-based theory originally developed to explain variations in testosterone-behavior relations in birds. The conclusions were that the theory could explain many of the human findings, including changes in testosterone following sexual and competitive interactions, and a decline in testosterone following paternal involvement with infants.

[6] Archer J: The behavioural biology of aggression. Cambridge, UK: Cambridge University Press, 1988. 
[7] Halpern CT, Udry JR, Campbell B, Suchindran C: Relationships between aggression and pubertal increases in testosterone: A panel analysis of adolescent males. Soc Biol 1994, 40, $8-24$.

[8] Enter D, Spinhoven P, Roelofs K: Alleviating social avoidance: Effects of single dose testosterone administration on approach-avoidance action. Horm Behav 2014, 65: 351-354. [9] Terburg D, Aarts H, van Honk J: Testosterone affects gaze aversion from angry faces outside of conscious awareness. Psychol Sci 2012: 23: 459-463.

[10] van Honk J, Tuiten A, Hermans EJ, Putman P, Koppeschaar H, Thijssen J...van Dooren L: A single administration of testosterone induces cardiac acceleration response to angry faces in healthy young women. Behav Neurosci 2001, 115: 238-242.

[11] Hermans EJ, Ramsey NF, van Honk J: Exogenous testosterone enhances responsiveness to social threat in the neural circuitry of social aggression in humans. Biol Psychiatry 2008, 63: $263-270$.

[12] van Wingen GA, Zylick SA, Pieters S, Mattern C, Verkes RJ, Buitelaar JK, Fernandez G: Testosterone increases amygdala reactivity in middle-aged women to a young adulthood level. Neuropsychopharmacology 2009, 34: 539-547.

[13] van Wingen GA, Ossewaarde L, Backstrom T, Hermans EJ, Fernandez G: Gonadal hormone regulation of the emotion circuitry in humans. Neuroscience 2011, 191: 38-45.

[14] Wingfield JC, Hegner RE, Dufty Jr AM, Ball GF: The ‘challenge hypothesis': theoretical implications for patterns of testosterone secretion, mating systems, and breeding strategies. Am Naturalist 1990, 136: 829-846. 
[15] Wingfield JC, Lynn SE, Soma KK: Avoiding the 'costs' of testosterone: Ecological bases of hormone-behavior interactions. Brain, Behav Evol 2001, 57: 239-151.

[16] Hirschenhauser K, Oliveira RF: Social modulation of androgens in male vertebrates: Meta-analysis of the challenge hypothesis. Animal Behav 2006, 71: 265-277.

[17] Archer J, Carré JM: Testosterone and aggression. In B. Bushman (Ed.), The Social Psychology of aggression and violence (Frontiers of Social Psychology series: pp. 90-104). New York: Psychology Press. 2016

[18] Gettler LT, McDade TW, Feranil AB, Kuzawa CW: Longitudinal evidence that fatherhood decreases testosterone in human males. PNAS 2011, 108: 16194-16199.

[19] Gettler LT: Applying socioendocrinology to evolutionary models: Fatherhood and physiology. Evolutionary Anthropology 2014, 23: 146-160.

[20] Eisenegger C, von Eckardstein A, Fehr E, von Eckardstein S: Pharmokinetics of testosterone and estradiol gel preparations in healthy young men. Psychoneuroendocrinology 2013, 38: 171-178.

* [21] Goetz SMM, Tang L, Thomason ME, Diamond MP, Hariri AR, Carré JM: Testosterone rapidly increases neural reactivity to threat in healthy men: A novel two-step pharmacological challenge paradigm. Biol Psychiatry 2014, 76: 324-331.

This paper used a novel two-step pharmacological challenge paradigm in which testosterone concentrations were first suppressed to a hypogonadal state using a gonadotropin releasing hormone (GnRH) antagonist and then increased using a single dose of testosterone. Functional 
neuroimaging data indicated that this manipulation rapidly increased threat-related amygdala function in healthy young men.

[22] Zak PJ, Kurzban R, Ahmadi S, Swerdloff RS, Park J, Efremidze L...Matzner, W:

Testosterone administration decreases generosity in the Ultimatum Game. PLoS ONE 2009, 4: e8330.

* [23] Carré JM, Olmstead NA: Social neuroendocrinology of human aggression: Examining the role of competition-induced testosterone dynamics. Neuroscience 2015, 286: 171-186.

This review paper provides an updated synthesis of the relationship between context dependent changes in testosterone concentrations and human aggressive behavior. The general conclusion of this paper is that acute changes in testosterone, rather than baseline testosterone concentrations, reliably map onto variation in human aggression. This paper also proposed neural mechanisms through which testosterone may modulate human aggression.

[24] Cherek DR, Tcheremissine OV, Lane SD: Psychopharmacology of human aggression: laboratory and clinical studies. In: Nelson RJ, editor. Biology of Aggression. New York: Oxford University Press, 424-446. 2006

[25] Carré JM, Putnam SK, McCormick CM: Testosterone responses to competition predict future aggressive behavior at a cost to reward in men. Psychoneuroendocrinology 2009, 34: 561-570.

[26] Carré JM, Campbell JA, Lozoya E, Goetz SM, Welker KM: Changes in testosterone mediate the effect of winning on subsequent aggressive behavior. Psychoneuroendocrinology 2013, 38: 2034-2041. 
[27] Carré JM, Iselin AMR, Welker KM, Hariri AR, Dodge KA: Testosterone reactivity to provocation mediates the effect of early intervention on aggressive behavior. Psychol Sci 2014, 25: 1140-1146.

[28] Trainor BC, Bird IM, Marler CA: Opposing hormonal mechanisms of aggression revealed through short-lived testosterone manipulations and multiple winning experiences. Hormones and Behavior 2004, 45: 115-121.

[29] Gleason ED, Fuxjager MJ, Oyegbile TO, Marler CA: Testosterone release and social context: When it occurs and why. Front Neuroendocrinol 2009, 30: 460-469.

[30] Wood RI, Newman SW: Androgen receptor immunoreactivity in the male and female Syrian hamster brain. J Neurobiol 1999, 39: 359-370.

[31] Fernández-Guasti A, Kruijver FP, Fodor M, Swaab DF: Sex differences in the distribution of androgen receptors in the human hypothalamus. J Comp Neurol 2000, 425: 422-435. [32] Roselli CE, Klosterman S, Resko JA: Anatomic relationships between aromatase and androgen receptor mRNA expression in the hypothalamus and amygdala of adult male cynomolgus monkeys. J Comp Neurol 2001, 439: 208-223.

[33] Blair RJR: Neuroimaging of psychopathy and antisocial behavior: A targeted review. Current Psychiatry Reports 2010, 12: 76-82.

* [35] Carré JM, Geniole SN, Ortiz TL, Bird BM, Videto A, Bonin PL: Exogenous testosterone rapidly increases aggressive behavior in dominant and impulsive men. Biol Psychiatry in press. 
This paper is the first to demonstrate that a single dose of testosterone rapidly (within 60 mins) modulates aggressive behaviour in healthy young men. Importantly, this effect was moderated by individual differences in self-reported trait dominance and self-control. Results indicated that testosterone potentiated aggressive behavior, but only among dominant and/or impulsive men.

[36] Mehta PH, van Son V, Welker KM, Prasad S, Sanfey AG, Smidts A, Roelofs K: Exogenous testosterone in women enhances and inhibits competitive decision-making depending on victory-defeat experience and trait dominance. Psychoneuroendocrinology 2015, 60: 224 236.

[37] Slatcher RB, Mehta PH, Josephs RA: Testosterone and self-reported dominance interact to influence human mating behavior. Soc Psychol Pers Sci 2011, 2: 531-539.

[38] Burnham TC: High-testosterone men reject low ultimatum game offers. Proc Biol Sci 2007, 274: 2327-2330.

[39] Mehta PH, Beer J: Neural mechanisms of the testosterone-aggression relation: the role of the orbitofrontal cortex. J Cog Neurosci 2010, 22: 2357-2368. http://dx.doi/org/ 10.1162/jocn.2009.21389

[40] Cueva C, Roberts RE, Spencer TJ, Rani N, Tempest M, Tobler PN, Herbert J, Rustichini A: Testosterone administration does not affect men's rejections of low ultimatum game offers or aggressive mood. Horm Behav 2017, 87: 1-7.

[41] Eisenegger C, Naef M, Snozzi R, Heinrichs M, Fehr E: Prejudice and truth about the effect of testosterone on human bargaining behaviour. Nature, 2010 463:356-359. 
[42] Kopsida E, Berrebi J, Petrovic P, Ingvar M: Testosterone administration related differences in brain activation during Ultimatum Game. Front Neurosci 2016, 10: 66.

[43] Dreher J-C, Dunne S, Pazderska A, Frodl T, Nolan JJ, O’Doherty JP: Testosterone causes both prosocial and antisocial status-enhancing behaviors in human males. PNAS 2016, 113: 11633-11638.

[44] Dabbs J, Jurkovic G, Frady R: Salivary testosterone and cortisol among late adolescent male offenders. J Abnorm Child Psychol 1991, 19: 469-478.

[45] Popma A, Vermeiren R, Geluk CA, Rinne T, van den Brink W, Knol DL, Jansen LMC, van England H, Doreleijers TAH: Cortisol moderates the relationship between testosterone and aggression in delinquent male adolescents. Biol Psychiatry 2007, 61: 405-411..

[46] Geniole SN, Busseri MA, McCormick CM: Testosterone dynamics and psychopathic personality traits independently predict antagonistic behavior toward the perceived loser of a competitive interaction. Horm Behav 2013, 64: 790-798.

[47] Mazur A, Booth A: Testosterone is related to deviance in male army veterans, but relationships are not moderated by cortisol. Biol Psychol 2014, 96: 72-76.

[48] Denson TF, Mehta PH, Ho Tan D: Endogenous testosterone and cortisol jointly influence reactive aggression in women. Psychoneuroendocrinology 2013, 38: 416-424..

[49] Welker KM, Lozoya E, Campbell JA, Neumann CS, Carré JM: Testosterone, cortisol, and psychopathic traits in men and women. Phys Behav 2013, 129: 230-236.

[50] Pfattheicher S: Illuminating the dual-hormone hypothesis: About chronic dominance and the interaction of cortisol and testosterone. Agg Behav 2017, 43: 85-92. 
